\title{
Use of Biologically Active 3D Matrix for Extensive Skin Defect Treatment in Veterinary Practice: Case Report
}

\author{
Elena Yu Zakirova ${ }^{1 *}$, Dmitry V. Shalimov ${ }^{2}$, Ekaterina E. Garanina ${ }^{1 \dagger}$, \\ Margarita N. Zhuravleva ${ }^{1}$, Catrin S. Rutland ${ }^{3 \dagger}$ and Albert A. Rizvanov ${ }^{1 *}$ \\ ${ }^{1}$ Department of Exploratory Research, Scientific and Educational Center of Pharmaceutics, Institute of Fundamental \\ Medicine and Biology, Kazan Federal University, Kazan, Russia, ${ }^{2}$ Veterinary Clinic "6 Elephants", Kazan, Russia, ${ }^{3}$ Faculty of \\ Medicine, School of Veterinary Medicine and Science, University of Nottingham, Nottingham, United Kingdom
}

\section{OPEN ACCESS}

Edited by:

Fausto Cremonesi,

University of Milan, Italy

Reviewed by:

Marco Patruno,

University of Padova, Italy Francisco Miguel Sanchez Margallo, Centro de Cirugía de Mínima Invasión

Jesús Usón, Spain

${ }^{*}$ Correspondence:

Elena Yu Zakirova

lenahamzina@yandex.ru

Albert A. Rizvanov

albert.rizvanov@kpfu.ru orcid.org/0000-0002-9427-5739

†Ekaterina E. Garanina orcid.org/0000-0002-4134-0445

Catrin S. Rutland orcid.org/0000-0002-2009-4898

Specialty section:

This article was submitted to Veterinary Regenerative Medicine,

a section of the journal

Frontiers in Veterinary Science

Received: 26 September 2018

Accepted: 21 February 2019

Published: 15 March 2019

Citation:

Zakirova EY, Shalimov DV

Garanina EE, Zhuravleva MN, Rutland CS and Rizvanov AA (2019)

Use of Biologically Active 3D Matrix for

Extensive Skin Defect Treatment in Veterinary Practice: Case Report.

Front. Vet. Sci. 6:76.

doi: 10.3389/fvets.2019.00076
Objectives: Large full-thickness skin defects represent a serious veterinary problem.

Methods: We have developed novel bioactive 3D-matrixes based on fibrin glue Tissucol (Baxter), containing the combination of the adenoviral constructs with genes vascular endothelial growth factor 165 (VEGF165) and fibroblast growth factor two (FGF2; construct Ad5-VEGF165 + Ad5-FGF2) or multipotent mesenchymal stem cells, genetically modified with these constructs.

Results: In vitro studies confirmed the biosynthesis of VEGF165 and FGF2 mRNA in the transduced cells. Ad5-VEGF165 + Ad5-FGF2- transduced multipotent mesenchymal stem cells showed an enhanced capacity to form capillary-like tubes in vitro. Bioactive 3D-matrix application enhanced granulation tissue formation and epithelialization of non-healing, large bite wounds in a dog. Successful wound healing was observed with a positive clinical outcome for the canine patient. This research and application of regenerative gene therapy alongside a novel bioactive 3D-matrix shows promising clinical applications for the future in both dogs and other mammals including humans.

Keywords: mesenchymal stem cells, fibrin glue, 3D matrix, VEGF165, FGF2

\section{INTRODUCTION}

Skin of pets such as dogs and cats is usually movable and relatively excessive. However, in veterinary practice, there are cases when it is impossible to close the skin defect with a simple apposition of wound edges (1). For example, this situation is observed in cases of large defects, wounds on distal parts of extremities or in oncology practice after radical resection of tumors. In veterinary surgery skin grafts, myocutanous flaps plastic surgery techniques are used for the closing of such skin defects (2). Unfortunately, in cases where extensive skin damage is a factor these methods are inapplicable. To treat such wounds we have developed, a bioactive 3D matrix based on fibrin glue, multipotent mesenchymal stem cells (MSCs), or/and vegf $165 a$ and $f g f 2$ genes containing adenoviral constructs and tested them both in vitro and in the veterinary clinic.

Healing of skin defects is a stepwise process, including hemostasis and inflammation in the early stages, followed by cellular proliferation and extracellular matrix deposition and ending with remodeling and scar formation (3). Wound healing requires the coordinated work of cells, growth factors, and extracellular matrix components. MSCs can influence all stages of wound healing process. They regulate immune responses and inflammation, and recruit macrophages, lymphocytes, and granulocytes to the inflammation area. 
MSCs also enhance migration and proliferation of keratinocytes and endothelial cells and secret growth factors [including vascular endothelial growth factor (VEGF), basic fibroblast growth factor/fibroblast growth factor 2 (bFGF/FGF2), epidermal growth factor (EGF), keratinocyte growth factor (KGF)] during proliferation phase of healing. MSCs can also differentiate into various lineages of mesenchymal origin and form dermal and hypodermal cell compartments $(4,5)$.

Angiogenesis is a key element of proliferative phase of wound healing because the delivery of oxygen and nutrients is crucial for reparation process. One of the most important proangiogenic factors is VEGF (6). VEGF stimulates DNA synthesis and proliferation and is involved in anti-apoptotic signaling pathways. It promotes proliferation and migration of endothelial and smooth muscle cells, monocytes, macrophages, and granulocytes involved in the wound healing process, stimulates the activity of pericytes and stabilizes newly formed vessels (7).

Recently it has been shown that VEGF stimulates wound healing not only due to its proangiogenic effects. In vitro studies have demonstrated that keratinocytes express both VEGF and its' receptors and VEGF directly stimulates their proliferation, migration and survival $(8,9)$. This factor stimulates migration of macrophages and cell debris uptake on early stages of wound healing and induces macrophage apoptosis during the resolution of inflammation $(10,11)$. FGF2 is a classic mitogen, which stimulates proliferation of target cells (including endothelial cells, fibroblasts, and keratinocytes), their migration and differentiation and also has a cytoprotective effect (12).

We developed a model of bioactive 3D-matrix based on fibrin glue Tissucol (Baxter), containing in one case MSCs, modified with a combination of adenoviral constructs with VEGF165 and FGF2 genes (MSC + Ad5-VEGF165 + Ad5-FGF2), and in the second case-the combination of the adenoviral constructs with genes VEGF165 and FGF2 (Ad5-VEGF165 + Ad5-FGF2) without MSCs. The aim of our study was to prove experimentally the feasibility and effectiveness of using a bioactive 3Dmatrixes based on fibrin glue Tissucol (Baxter), containing the combination of the adenoviral constructs with genes VEGF165 and FGF2 (Ad5-VEGF165 + Ad5-FGF2) or MSC modified with the adenoviral constructs in a veterinary surgery setting for closing full-thickness skin defects in dogs.

\section{MATERIALS AND METHODS}

All procedures were performed in accordance with international, national, and/or institutional guidelines for the care and use of animals were followed. The Institutional Review Board of the Kazan Federal University approved this study (protocol No3; date 05.05.2015). A homeless dog, male, aged $\sim 3-5$ years, was in the custody of the animal protection community "Zoozabota" which took care of the animal and gave written informed consent. The procedure was only undertaken after conventional methods used to assist the dog had not helped recovery. The animal was too cachectic to harvest fat from. The mass of dog was $5 \mathrm{~kg}$. During surgery the animal was kept anesthetized with $0.1-0.15 \mathrm{mg} / \mathrm{kg}$ Zoletil-100 (Tiletamine Hydrochloride, Zolazepam Hydrochloride, Virbac, France) and 1-3 mg/kg XylaVet (Xylazine Hydrochloride, Holland) under full veterinary care.

\section{MSC Isolation and Immunophenotyping}

Due to the severity of the patient's condition we had to use allogenic dog adipose derived MSC for the generation of biologically active 3D matrix. MSCs were isolated using standard techniques as described previously (13). Briefly, the adipose tissue of donor dogs' greater omentum was isolated in a veterinary operating room during ovariohysterectomy under sterile conditions. The tissue was transported in a sterile flask with sterile $0.9 \% \mathrm{NaCl}$ for further work in cell culture laboratory (within $2 \mathrm{~h}$ ). The adipose tissue was cut to pieces of about 1 $\mathrm{cm}^{2}$ in a laminar flow biosafety cabinet under sterile conditions. Blood cells were washed out using centrifugation at $500 \times \mathrm{g}$ for $5 \mathrm{~min}$. Adipose tissue was then incubated with the sterile solution of crab hepatopancreas collagenase (Biolot, Russia) to a final concentration of $0.2 \%$ for an hour at $37^{\circ} \mathrm{C}$ with shaking at $200 \mathrm{rpm}$. Next, the homogenate was centrifuged for $5 \mathrm{~min}$ at $500 \times \mathrm{g}$, the enzymatic solution was then decanted and the cell pellet containing the stromal-vascular fraction was suspended in Dulbecco's phosphate-buffered saline (DPBS) solution and centrifuged twice for $5 \mathrm{~min}$ each at $500 \times \mathrm{g}$ to remove any residual enzymes. The obtained cells were cultured in $\alpha$-MEM medium with $10 \%$ fetal bovine serum (FBS), 100 $\mathrm{U} / \mathrm{ml}$ penicillin, $100 \mu \mathrm{g} / \mathrm{ml}$ streptomycin, and $2 \mathrm{mM} \mathrm{L}$-glutamine (all from PanEco, Russia). The culture medium was changed every 3 days. Immunophenotyping of MSCs was performed using antibodies CD10 FITC, CD71 FITC (Sorbent, Russia), CD34 AF488, CD45 AF488, CD105 AF488 (Biolegend), CD44, stro1, and Thy-1 (Santa Cruz, USA) according to manufacturers' protocols. Results were evaluated using a confocal fluorescence scanning microscope LSM 780 (ZEISS, Germany).

\section{Adenoviruses Ad5-VEGF165 and Ad5-FGF2 Preparation}

Recombinant replication-defective adenoviruses Ad5-VEGF165 and Ad5-FGF2 were obtained using Gateway cloning technology as reported previously (14). Vegf165 gene cDNA fragments were amplified using thermocycler C1000 Thermo Cycler (BioRad), Phusion High fidelity DNA Polymerase (Finnzymes, Thermo Fisher Scientific, USA), and specific primers (Synthol, Russia). The purified PCR amplification products were cloned into a plasmid vector pENTR-D/TOPO (Invitrogen Thermo Fisher Scientific, USA) using topoisomerase followed by transformation into competent $E$. coli Top 10 cells. PCR screening of the colonies was carried out using vector-specific primers. Target recombinant plasmid uptake was confirmed by sequencing and restriction analysis.

PCR amplification of $f g f 2$ gene fragments was carried out in two stages. Initially attB-sites were connected using genespecific primers hFGF2-attB1 and hFGF2-attB2 (15). The second stage was to increase the length of the nucleotide attsites sequence which was performed using the adapter primer GW-attB1 and GW-attB2 (Liteh, Russia). BP- recombination 
was performed according to a standard protocol (Invitrogen Thermo Fisher Scientific, USA) followed by transformation into competent cells E. coli Top 10. PCR screening of colonies and target recombinant plasmid uptake confirmations were carried out as described above.

LR-recombination of gene cDNA from donor plasmids pENTR- VEGF165 and pDONR-FGF2 into vectors plasmid pAd/CMV/V5-Dest (Invitrogen Thermo Fisher Scientific, USA) was performed to create adenoviral expression constructs. Transformation of competent E. coli cells, the PCR screening of colonies and target recombinant plasmid receiving confirmation were carried out as described above.

To produce recombinant adenovirus Ad5-VEGF165 and Ad5-FGF2, adenoviral plasmid vector was transferred into a linear form using a restriction enzyme PacI. HEK293A cells were transfected with purified linear plasmids using transfection reagent TurboFect. On the 10th day after transfection, fields of cytopathic effect became apparent and the cell suspension was collected. Cells were cryolysed, cell debris was eradicated using centrifugation to prepare a crude viral lysate. Amplification of recombinant adenoviruses Ad5-VEGF165 and Ad5-FGF2 was performed in HEK293A cell cultures. Adenoviruses were concentrated using ultracentrifugation in cesium chloride density gradient. Viruses were purified from cesium salts by dialysis. Determination of viral titers was performed by its capacity to form plaques on agarose layer.

\section{RT-PCR}

Passage 3 MSCs were transfected with Ad5-VEGF165 and Ad5FGF2 at 100 MOI each. The transcriptional activity of genes vegf 165 and $f g f 2$ were evaluated 24 h post-infection by qPCR. Specific primers, probes and nucleotide sequences were described previously (15). Serial dilutions of cDNA synthesized from mRNA of the transfected cells were used to construct a standard curve and determine the level of gene expression. The gene expression level of non-transfected cells was taken as 100\%.

\section{Matrigel Tube-Formation Assay}

Matrigel $^{\text {TM }}$ tube-formation assay with Ad5-VEGF165 and Ad5FGF2 co-transfected cells and non-transfected (control) cells was performed as described previously (16). Briefly, 10,000 MSCs co-transfected with Ad5-VEGF165 and Ad5-FGF2 or 10,000 non-transfected cells per well in triplicates were seeded in a 96-well plate pre-coated with $50 \mu$ l of Matrigel ${ }^{\circledR}$ Growth Factor Reduced Basement Membrane Matrix (Cat. \#356231, Becton Dickinson, USA) in DMEM/F12 media supplemented with $1 \%$ FBS. The plates were incubated at $37^{\circ} \mathrm{C}$ in a humidified atmosphere containing $5 \% \mathrm{CO}_{2}$ for $16 \mathrm{~h}$. Tube formation was evaluated using microscopy and ImageJ software.

\section{Bioactive 3D Matrix Preparation}

$3 \mathrm{D}$ bioactive matrix was formed immediately prior to application to the wound. Fibrin glue Tissucol was used as a matrix basement. Two types of matrix were used. The first type of matrix consisted of 3,000,000 genetically modified MSCs and $1 \mathrm{ml}$ of Tissucol. MSCs were co-transfected with Ad5-VEGF165 and Ad5-FGF2 at MOI 100 each the day before application. Cell suspension, thoroughly washed from media and viruses by centrifugation, was mixed with fibrin glue and uniformly applied to the wound surface. The second type of matrix was prepared from $1 \mathrm{ml}$ of Tissucol and a mixture of Ad5-VEGF165 and Ad5-FGF2 viruses in amounts equivalent to those used for MSC transfection.

\section{Statistical Analysis}

Statistical analysis was performed using Student's $t$-test in Microsoft Excel 2007 software, $P \leq 0.05$ was considered statistically significant.

\section{RESULTS}

\section{In vitro Studies}

Adenoviruses Ad5-VEGF165 and Ad5-FGF2 were prepared using standard methods of molecular genetics and used for gene therapy as part 3D-matrix or to modify the MSCs with MOI 100. MSCs isolated from dog adipose tissue as was described previously (17) had a fibroblast-like morphology, and expressed markers of the MSCs CD10, CD71, CD44, CD105, stro-1, Thy1 , and did not express the hematopoietic markers CD34 or CD45 (Figure 1).

Biosynthesis of VEGF and FGF2 mRNA in transduced cells was confirmed after $24 \mathrm{~h}$ after modification of MSC with
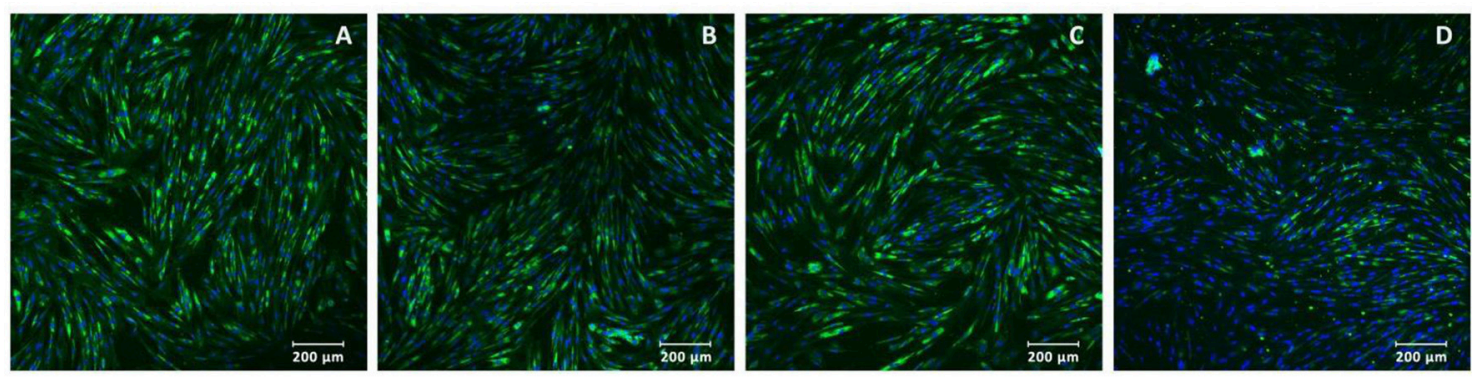

FIGURE 1 | Immunocytochemistry of multipotent mesenchymal stem cells: (A) stro-1, (B) Thy-1, (C) CD10, and (D) CD105 expressed in green (488 wavelength). Nuclei were stained with DAPI (4',6-diamidino-2-phenylindole, blue in color). Magnification: $\times 200$. 


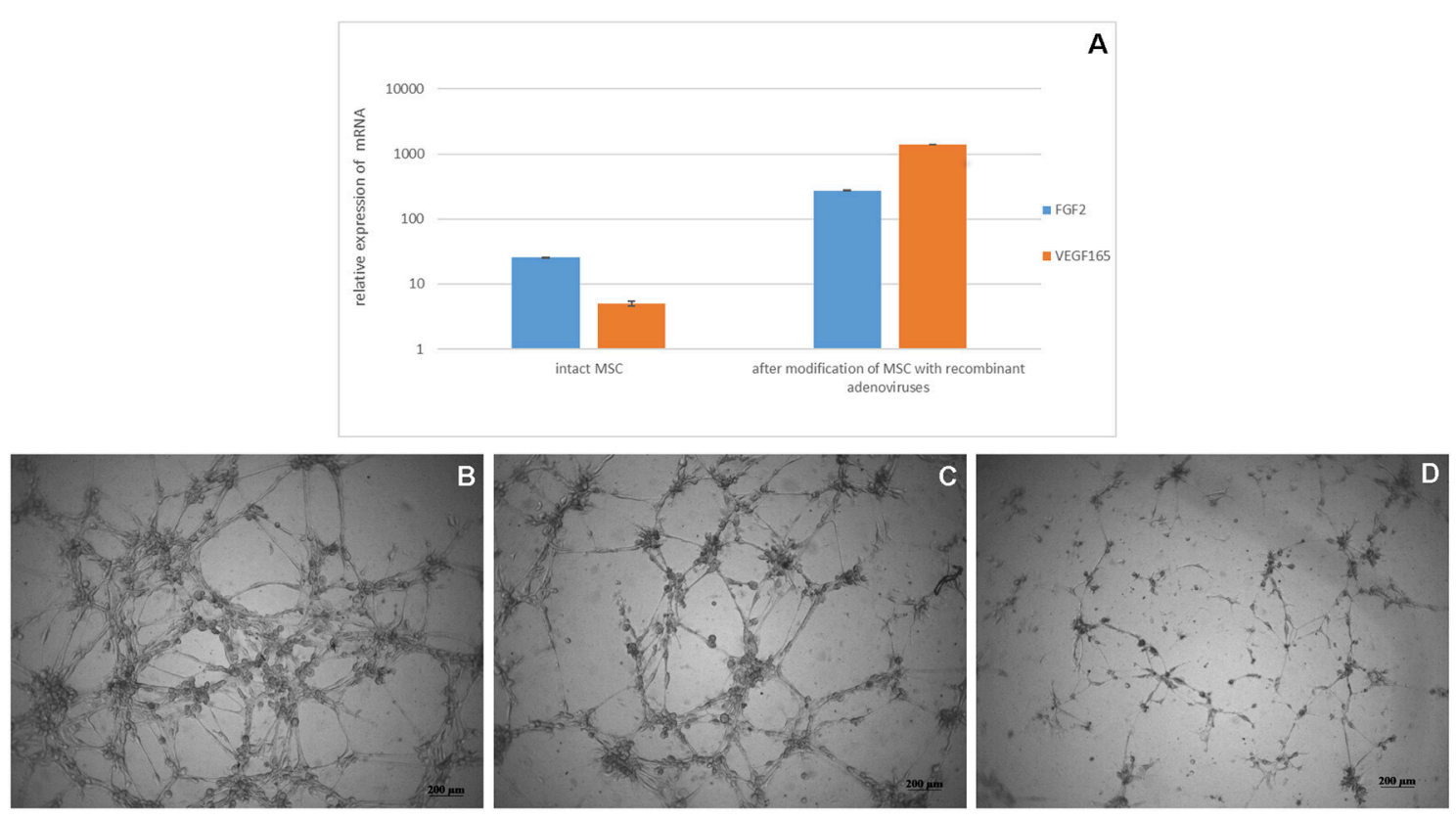

FIGURE 2 | (A) Analysis of VEGF 165 and FGF2 mRNA expression in genetically modified MSCs. Data are presented as Mean \pm standard error of the mean. Expression was normalized to 18 s rRNA. Matrigel ${ }^{\text {TM }}$ capillary-like structure formation by genetically modified canine MSCs (B) Ad5-VEGF165 and Ad5-FGF2 co-transfected cells in DMEM/F12 media supplemented with 1\% FBS (C) non-transfected cells on nutritious medium (positive control) in DMEM/F12 media supplemented with $1 \% \mathrm{FBS}$ and $10 \mathrm{ng} / \mathrm{ml}$ recombinant VEGF, and (D) non-transected cells on poor medium (negative control) in DMEM/F12 media supplemented with $1 \%$ FBS.

recombinant adenoviruses (Figure 2A). MSCs-Ad-VEGF165FGF2 had a higher (70 \pm 5 units/well) capacity to form capillarylike structures on Matrigel ${ }^{\mathrm{TM}}$ as compared with intact cells (47 \pm 5 units/well, Figures 2A-D), $p<0.05$.

\section{In vivo Clinical Case Results}

In vivo biologically active $3 \mathrm{D}$ matrix was tested in two morphologically similar non-healing full-thickness bite wounds measuring about $70 \mathrm{~cm}^{2}$ each in the back and groin areas of a medium sized adult dog. The numerous bite wounds were received during fights between the patient and another dog. Immediately after injury, the wounds were sanitized and sutured in a veterinary clinic. The post-operative period proved complicated with extensive necrosis of the skin at the wound edges. Necrotic tissue was dissected away, as a result the closure of the wounds by matching their edges became impossible. The effect of standard practice conservative therapy was insignificant: after 2 weeks of treatment marginal necrosis was observed and granulations were almost absent. There was no wound contraction either. As the patient had not responded to standard veterinary care, treatment with the new therapy was administered. Necrotic skin was dissected and tissues were flayed until pinpoint bleeding (Figure 3).

In order to stimulate the regeneration of tissue growth around the wounds, the biologically active matrix was applied. The wound on the back was covered with matrix based on Tissucol fibrin glue containing 3 million MSCs transfected with
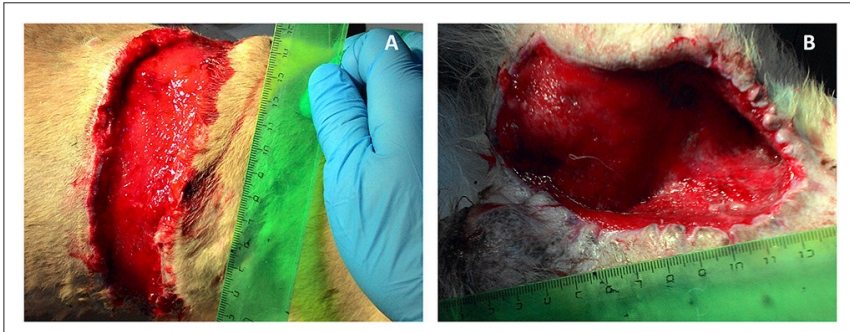

FIGURE 3 | Canine wounds prior to 3D matrix application: (A) back, (B) groin.

combination of Ad5-VEGF165 and Ad5-FGF2 (MOI 100 for each construct). Allogenic MSCs had to be used due to the severity of the patients' body condition. The wound in the groin was covered with another type of matrix containing Tissucol fibrin glue, Ad5-VEGF165 and Ad5-FGF2 in amounts equivalent to those used to transduce the MSCs. Wounds were closed with occlusive dressings. To prevent wound contamination, Baytril 5\% (enrofloxacin, Bayer Corporation, USA.) antibiotic was subcutaneously injected in dose $0.1 \mathrm{ml} / \mathrm{kg}$ once a day for 7 days.

On the 3rd day after 3D matrix application the dressings were removed. Juicy red granulations, edge epithelization up to 3$4 \mathrm{~mm}$, wound contraction and minor exudation were observed. On the 7th day, edge epithelization of from $6-7$ to $10 \mathrm{~mm}$ had been achieved. There were no signs of necrosis or inflammation throughout the entire healing period. The wound on dogs' back 

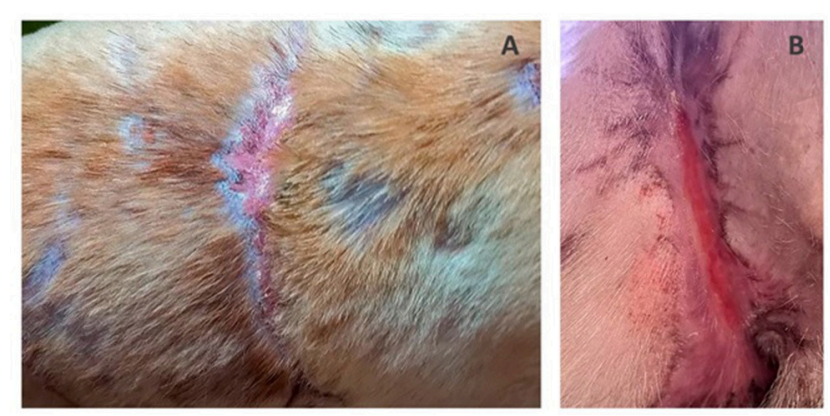

FIGURE 4 | Canine wounds 1 month after 3D-matrix application: (A) back, (B) groin.

was completely healed after 1 month and the wound in the groin healed within 1.5 months with normal non-hypertrophic scar formation (Figure 4). Following successful treatment the dog was adopted and rehomed as a pet.

\section{DISCUSSION}

Large full-thickness skin defects pose a serious medical and veterinary problem. In medicine if autodermoplasty is impossible, skin can be obtained from tissue bank. In veterinary medicine this is presently impossible. In addition large skin defects cause a vicious circle: the bigger the total lesion area, the worse the patients general condition, the worse local regeneration of damaged skin.

The effects of MSC, various growth factors and genetic constructs expressing them on the skin regeneration process have been studied for a long time. Positive effects of MSCs, VEGF, and FGF2 application on regeneration of skin defects in laboratory animals and in the clinic have been shown (18). Application of MSCs improves wound closure by accelerating epithelialization and increasing angiogenesis and granulation tissue formation $(19,20)$. The most beneficial effect of exogenous MSCs on wound healing was shown in cases of chronic wounds with poor trophicity (diabetic) $(21,22)$.

There is also evidence that VEGF and FGF2 can promote wound healing. VEGF is highly expressed in normally healing wounds but its excessive introduction doesn't significantly accelerate would closure and epithelialization (23, 24). However, in delayed healing diabetic wounds or ischemic skin flaps VEGF delivery enhances skin regeneration $(25,26)$. FGF2 is normally expressed in healthy skin an increased expression is observed upon skin damage. A number of studies have shown that FGF2 promotes tissue regeneration, and its deficiency causes wound healing disorders (27). Therefore, it has been suggested that FGF2 reduces hypertrophic scar formation (28).

There is a lack of studies of combined use of several growth factors together with a carrier matrix. Research has shown increased angiogenesis and keratinocyte growth after application of VEGF and FGF2-loaded collagen biomatrix on skin defects created on the back of fetal lambs (29). Our group has also had positive previous experiences of the use of genetic constructs containing the combination of VEGF and FGF2 genes in the treatment of chronic wounds (such as trophic ulcers in diabetes) (30) and injuries to tendons or ligaments in domestic animals $(31,32)$.

Our present study shows enhanced wound healing by combining the use of fibrin glue and MSCs, modified for increased production of VEGF165 and FGF2, or adenoviral constructs Ad5-VEGF165 and Ad5-FGF2. Our in vitro studies confirmed the biosynthesis of mRNA of vegf165 and fgf2 in the transduced MSCs. The resulting proteins VEGF and FGF2 exhibited their normal physiological activity. In addition they stimulated the formation of capillary-like tubes on Matrigel ${ }^{\mathrm{TM}}$, which is equivalent to the process of angiogenesis in vivo.

Upon application to wounds in a patient, satisfactory clinical results were achieved. Non-healing large bitten wounds were treated and enhanced granulation tissue formation, rapid epithelialization and wound contraction were observed and full recovery was achieved in a relatively short period of time. The difference in healing rate of two wounds (4 weeks for the back and 6 weeks for the groin) could be due to the location and shape of the wounds and/or MSCs secretion of the various biologically active substances which stimulated regeneration. These results highlight the need to further studies to investigate differing wound types in more patients as it shows great promise as a future treatment technique.

In conclusion the present clinical case has shown that fibrin glue based 3D matrices enhanced with Ad5-VEGF165 and Ad5-FGF2 or MSCs, transfected with Ad5-VEGF165 and Ad5FGF2, have beneficial effect in the treatment of large nonhealing wounds. This provides promising avenues of treatment for wounds and other conditions requiring tissue regeneration in animals.

\section{AUTHOR CONTRIBUTIONS}

EZ and AR contributed toward the conception and design of the study. All authors contributed toward data acquisition, analysis, and/or interpretation of data and drafted the work or revised it critically for intellectual content, and approved the submitted version. AR was awarded the funding.

\section{FUNDING}

This study was supported by the Russian Government Program of Competitive Growth of Kazan Federal University. AR was supported by state assignment 20.5175.2017/6.7 from the Ministry of Education and Science of Russian Federation. Some of the experiments were conducted using the equipment belonging to the Interdisciplinary Center for Collective Use, the Interdisciplinary Center for Analytical Microscopy and the Pharmaceutical Research and Education Center, Kazan (Volga Region) Federal University, Kazan, Russia. 


\section{REFERENCES}

1. Heo S, Lee H, Kim NS. Use of a gracilis myocutaneous flap for reconstruction of a perineal defect in a dog: case report. Turkish J Vet Anim Sci. (2013) 37:366-8. doi: 10.3906/vet-1204-22

2. Erwin G, Handharyani E, Noviana D. Subjective and objective observation of skin graft recovery on Indonesian local cat with different periods of transplantation time. Vet World. (2016) 9:481-6. doi: 10.14202/vetworld.2016.481-486

3. Gurtner GC, Werner S, Barrandon Y, Longaker MT. Wound repair and regeneration. Nature. (2008) 453:314-21. doi: 10.1038/nature07039

4. Hocking AM, Gibran NS. Mesenchymal stem cells: paracrine signaling and differentiation during cutaneous wound repair. Exp Cell Res. (2010) 316:22139. doi: 10.1016/j.yexcr.2010.05.009

5. Shi M, Liu ZW, Wang FS. Immunomodulatory properties and therapeutic application of mesenchymal stem cells. Clin Exp Immunol. (2011) 164:1-8. doi: 10.1111/j.1365-2249.2011.04327.x

6. Johnson KE, Wilgus TA. Vascular endothelial growth factor and angiogenesis in the regulation of cutaneous wound repair. Adv Wound Care. (2014) 3:647-61. doi: 10.1089/wound.2013.0517

7. Byrne AM, Bouchier-Hayes DJ, Harmey JH. Angiogenic and cell survival functions of vascular endothelial growth factor (VEGF). J Cell Mol Med. (2005) 9:777-94. doi: 10.1111/j.1582-4934.2005.tb00379.x

8. Wilgus TA, Matthies AM, Radek KA, Dovi JV, Burns AL, Shankar R, et al. Novel function for vascular endothelial growth factor receptor1 on epidermal keratinocytes. Am J Pathol. (2005) 167:1257-66. doi: 10.1016/S0002-9440(10)61213-8

9. Brem H, Kodra A, Golinko MS, Entero H, Stojadinovic O, Wang VM, et al. Mechanism of sustained release of vascular endothelial growth factor in accelerating experimental diabetic healing. I Invest Dermatol. (2009) 129:2275-87. doi: 10.1038/jid.2009.26

10. Petreaca ML, Yao M, Ware C, Martins-Green MM. Vascular endothelial growth factor promotes macrophage apoptosis through stimulation of tumor necrosis factor superfamily member 14 (TNFSF14/LIGHT). Wound Rep Regen. (2008) 16:602-14. doi: 10.1111/j.1524-475X.2008.00411.x

11. Kearns MT, Dalal S, Horstmann SA, Richens TR, Tanaka T, Doe JM, et al. Vascular endothelial growth factor enhances macrophage clearance of apoptotic cells. Am J Physiol Lung Cell Mol Physiol. (2012) 302:L711-8. doi: 10.1152/ajplung.00116.2011

12. Ornitz DM, Itoh N. Fibroblast growth factors. Genome Biol. (2001) 2:reviews3005. doi: 10.1186/gb-2001-2-3-reviews3005

13. Zakirova EY, Azizova DA, Rizvanov AA, Khafizov RG. Case of applying allogenic mesenchymal stem cells of adipogenic origin in veterinary dentistry. J Anim Vet Adv. (2015) 14:1-4. doi: 10.3923/javaa.2015.140.143

14. Cherenkova EE, Fedotova VY, Islamov RR, Rizvanov AA. Creation of recombinant adenoviral and lentiviral genetic constructs using Gateway technology for expression of angiogenic and neuroprotective factors. Genes Cells. (2012) 7:164-8.

15. Islamov RR, Rizvanov AA, Mukhamedyarov MA, Salafutdinov Ii, Garanina EE, Fedotova VY, et al. Symptomatic improvement, increased life-span and sustained cell homing in amyotrophic lateral sclerosis after transplantation of human umbilical cord blood cells genetically modified with adeno-viral vectors expressing a neuro-protective factor and a neural cell adhesion molecule. Curr Gene Ther. (2015) 15:266-76. doi: 10.2174/1566523215666150126122317

16. Zhuravleva MN, Zakirova EY, Masgutov RF, Valiullin VV, Deev RV, Rizvanov AA. Effect of recombinant plasmid constructs encoding combinations of dog and horse vegf and bmp2 cDNAs on mesenchymal stem cell differentiation in vitro. Genes Cells. (2015) 10:27-32.

17. Zakirova EY, Zhuravleva MN, Masgutov RF, Usmanov RA, Rizvanov AA. Isolation, analysis, and application of authogenic adipose derived multipotential mesenchymal stromal cells from dog for therapy pseudoarthrosis of tibial bone. Genes Cells. (2014b) 9:70-5.

18. Xie XG, Zhang M, Dai YK, Ding MS, Meng SD. Combination of vascular endothelial growth factor-loaded microspheres and hyperbaric oxygen on random skin flap survival in rats. Exp Ther Med. (2015) 10:954-8. doi: 10.3892/etm.2015.2620
19. Maxson S, Lopez EA, Yoo D, Danilkovitch-Miagkova A, Leroux MA. Concise review: role of mesenchymal stem cells in wound repair. Stem Cells Transl Med. (2012) 1:142-9. doi: 10.5966/sctm.2011-0018

20. Martinello T, Gomiero C, Perazzi A, Lacopetti I, Gemignani F, Debenedictis GM, et al. Allogeneic mesenchymal stem cells improve the wound healing process of sheep skin. Bmc Vet Res. (2018) 14:202. doi: 10.1186/s12917-018-1527-8

21. Kong P, Xie X, Li F, Liu Y, Lu Y. Placenta mesenchymal stem cell accelerates wound healing by enhancing angiogenesis in diabetic GotoKakizaki (GK) rats. Biochem Biophys Res Commun. (2013) 438:410-9. doi: 10.1016/j.bbrc.2013.07.088

22. Dash SN, Dash NR, Guru B, Mohapatra PC. Towards reaching the target: clinical application of mesenchymal stem cells for diabetic foot ulcers. Rejuven Res. (2014) 17:40-53. doi: 10.1089/rej.2013.1467

23. Brown LF, Yeo KT, Berse B, Yeo TK, Senger DR, Dvorak HF, et al. Expression of vascular permeability factor (vascular endothelial growth factor) by epidermal keratinocytes during wound healing. J Exp Med. (1992) 176:1375-9. doi: 10.1084/jem.176.5.1375

24. Vranckx JJ, Yao F, Petrie N, Augustinova H, Hoeller D, Visovatti S, et al. In vivo gene delivery of Ad-VEGF121 to full-thickness wounds in aged pigs results in high levels of VEGF expression but not in accelerated healing. Wound Rep Regen. (2005) 13:51-60. doi: 10.1111/j.1067-1927.2005. 130107.x

25. Galeano M, Deodato B, Altavilla D, Cucinotta D, Arsic N, Marini H, et al. Adeno-associated viral vector-mediated human vascular endothelial growth factor gene transfer stimulates angiogenesis and wound healing in the genetically diabetic mouse. Diabetologia. (2003) 46:546-55. doi: 10.1007/s00125-003-1064-1

26. Wang XT, Avanessian B, Ma Q, Durfee H, Tang YQ, Liu PY. Enhancement of flap survival and changes in angiogenic gene expression after AAV2-mediated VEGF gene transfer to rat ischemic flaps. Wound Rep Regen. (2011) 19:498-504. doi: 10.1111/j.1524-475X.2011. 00705.x

27. Werner S, Grose R. Regulation of wound healing by growth factors and cytokines. Physiol Rev. (2003) 83:835-70. doi: 10.1152/physrev.2003. 83.3.835

28. Shi HX, Lin C, Lin BB, Wang ZG, Zhang HY, Wu FZ, et al. The anti-scar effects of basic fibroblast growth factor on the wound repair in vitro and in vivo. PLoS ONE. (2013) 8:e59966. doi: 10.1371/journal.pone.0059966

29. Roelofs L, Eggink A, Van Kuppevelt T, Wijnen R, Van Den Berg P, Crevels J, et al. Coverage of fetal skin defects with a collagen biomatrix loaded with growth factors in a sheep model. J Pediatr Urol. (2009) 5:19-20. doi: 10.1016/j.jpurol.2009.02.007

30. Mullin RI, Masgutov RF, Salafutdinov II, Rizvanov AA, Bogov AA. Combined treatment of throphic ulcer of the heel using vacuum therapy with direct gene therapy: case report. Genes Cells. (2013) 8:125-8.

31. Zakirova EY, Vasin NN, Zhuravleva MN, Rizvanov AA. Case report of application gene construction with VEGF and BMP2 in restoration of tear in the anterior cruciate ligament of a large breed dog. Genes Cells. (2014a) 9:93-5.

32. Kovac M, Litvin YA, Aliev RO, Zakirova EY, Rutland CS, Kiyasov AP, et al. Gene therapy using plasmid DNA encoding vascular endothelial growth factor 164 and fibroblast growth factor 2 genes for the treatment of horse tendinitis and desmitis. Case reports. Front Vet Sci. (2017) 4:168. doi: 10.3389/fvets.2017.00168

Conflict of Interest Statement: The authors declare that the research was conducted in the absence of any commercial or financial relationships that could be construed as a potential conflict of interest.

Copyright (C) 2019 Zakirova, Shalimov, Garanina, Zhuravleva, Rutland and Rizvanov. This is an open-access article distributed under the terms of the Creative Commons Attribution License (CC BY). The use, distribution or reproduction in other forums is permitted, provided the original author(s) and the copyright owner(s) are credited and that the original publication in this journal is cited, in accordance with accepted academic practice. No use, distribution or reproduction is permitted which does not comply with these terms. 